auxiliary staff who have been trained in diagnosis and treatment.

One area where this approach has been developed most widely is in northern Nigeria and was initiated by Ross. He carried out surveys, trained auxiliary staff and set up outpatient clinics in villages. Patients accepted this approach enthusiastically, whereas before there had been a poor response to treatment based on the leprosarium. In one area, 639 new patients appeared for treatment within 3 months of opening the clinics. There was little fear of stigma against the disease and Ross comments: "There is a degree of shame attached to infection by the disease. Nevertheless, leprosy is tolerated in village and social life and any fear of detection has been associated with the dread of being segregated which means separation from one's family". By 1968 there were 2,000 outpatient clinics throughout the northern region and most patients had access to treatment at an early stage. Unfortunately, few countries adopted such an approach so comprehensively; in many the leprosarium remains the only place where treatmenit can be obtained, patients have to travel long distances and they fear segregation. The numbers on treatment have remained low for these reasons and not because of lack of money as LEPRA claims in its advertisements. The cost of maintaining patients in institutions is enormously high and measures such as reconstructive surgery have added to the financial burden, making even less money available for work in outpatient clinics. Also, diagnosis is late; patients come late in the course of the disease and thus many are crippled and hence do not benefit from dapsone treatment.

Voluntary agencies in Europe collect more than $£ 2$ million annually for leprosy work, but most is still spent on institutional care-in May 1973, for example, the Sunday Times published an illustrated article showing the plight of severely crippled leprosy patients in India. At the same time LEPRA appealed for money. $£ 20,000$ was collected and in a letter to the Sunday Times on December 13, 1973, the Directior of LEPRA gave details of how this money was to be spent. All of it was to be used on institutional care, accommodation and food, and on enabling patients to learn a trade such as footwear and cloth making; little money will go to curing and preventing the disease. As most of the patients are already crippled they cannot benefit from dapsone treatment. While there is sympathy for these patients' needs, surely the bulk of the money should go to prevention and cure with sulphones, which LEPRA claims is its aim.

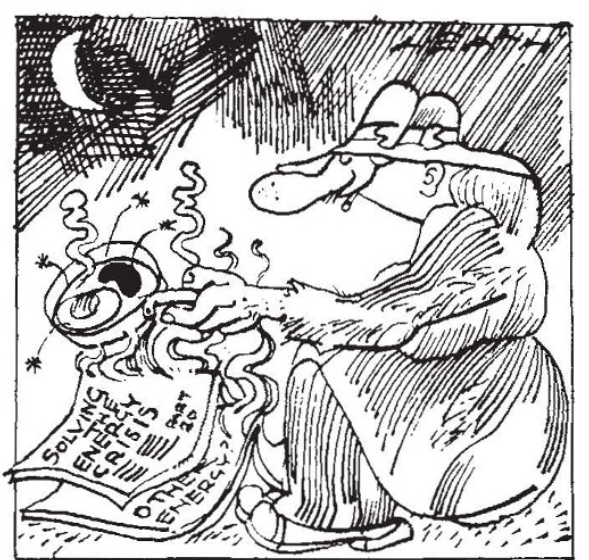

\section{Accounting for energy}

Dr Malcolm Slesser, Director of the Energy Studies Unit, Strathclyde University, sets out the basic principles of energy analysis.

I F economics is the science of scarcity 1 and substitution, energy analysis is no more than the application of economic theory to the one commodity in ultimate limitation on Earth-thermodynamic potential. Perhaps the greatest conceptual difference between economics, as we know it today, and energy analysis lies in the 'system boundary'. Economics sets up a boundary around the system of interest; in energy analysis the system boundary is the whole planet.

Within the framework of economic thought, the economic process will automatically stimulate the development of another energy resource as one resource is depleted and its marginal costs rise. In effect, economics treats the world as a closed system having access to limitless amounts of energy, whose acquisition takes only time, capital labour and technology. On the face of it, it is a good deal easier to justify the position of the economists than that of the energy analysists, but it can be looked at another way.

Any production process, such as building a road or manufacturing pigiron can only succeed if we inject capital, labour, materials and energy. Considering the properties of these inputs, capital is no more than labour, materials, capital and energy invested at an earlier time. If one goes on to examine every one of the inputs to any process one finds that these inputs are themselves the outcome of a process involving capital, labour, materials and energy. Indeed, the process of network analysis can go back and back until we find that the materials are ores in the ground or produce on the land and the energy is hydrocarbon locked in the
Earth or in deuterium atoms in a highly dilute state in the oceans; labour is mankind and capital has disappeared.

Although both energy and materials are mined and utilised, they have very different features. Materials are never destroyed; the iron molecule in iron ore is still an iron molecule when it is turned into steel and when it ultimately ends up as rust. Moreover, there can never really be a shortage of ores, since the oceans contain very large quantities. We are, however, long past that stage of global development at which ores can be obtained at sufficient rates simply by men labouring with picks and shovels. The energy required to win increasingly depleted ores and turn them into concentrated form will rise to enormous values. It is not the scarcity of the ores that is the problem.

When this thinking is applied to the two examples of making pig-iron and road building, it is certainly conceivable that, given enough poor and willing citizens, a motorway could be constructed by human labour alone. But no amount of human sweat can turn iron ore into iron, or iron into sophisticated machine tools. Though there is a well understood marginal energy cost for labour, so that the two can substitute one for the other to some extent, in the last analysis, energy does what labour cannot do. It carries out processes of transformation involving a decrease in entropy. Energy is irretrievably degraded once it has been used. All energy finishes up as waste heat, and must eventually be dissipated to the surrounding space. Labour, by contrast, is renewable and can also be upgraded through such processes as education and training. Also, as development has proceeded, labour, except in its most skilled forms, has become a surplus commodity in the greater part of the world.

Accordingly, energy analysts believe that it makes sense to measure the cost of the things done, not in money, which is after all nothing more than a highly sophisticated value judgement, but in terms of thermodynamic potential. On the other hand it is widely recognised amongst energy analysts that, as R. S. Berry has stated so succinctly, "if economists in the market place were to determine their shortages by looking further and further into the future, these estimates would come closer and closer to the estimates made by their colleagues, the thermodynamicists".

As energy analysis is concerned with the amount of global energy stock which must be sequestered to make a good or service, it is not enough to assess the amount of oil consumed to heat a house. What is of interest is the total amount of oil in the ground, to- 
gether with any other energy sources, that had to be used to make that house heating possible. Thus we also need to know the quantities of energy that were required to win the oil from the ground, bring it from the oil field, refine it and deliver it to the consumer. In the UK these processes add about $18 \%$ to the apparent energy requirement for fuel oil for home heating. The error in ignoring the energy requirements for supply are in this case small, because the direct energy costs are the major component. But if we apply the same error to UK agriculture, for example, the direct energy requirements are a mere $42 \%$ of the total amount of energy that must in the end have been sequestered in order to make UK agriculture possible. This will have included the energy to make the tractor (duly amortised), pesticides, fertilisers and so on, as well as an appropriate share of the energy to make the machines that make the fertilisers, tractors and so on.

Until August 1974, various practitioners of energy analysis were, of necessity, formulating their own rules. In that month the International Federation of Institutes of Advanced Study (IFIAS) held a workshop in Sweden, attended by twenty people from nine countries, at which the methodology and conventions of energy analysis were thrashed out. Its repont is now available (Workshop Report No. 6, IFIAS, Stockholm; £4), and the following remarks follow its recommendations.

Perhaps the most fundamental observation is that since our concern with energy is its ability to do work, the calorific or heating values of fuels are not really the quality of interest. Rather it is a more subtle thermodynamic quality known to engineers as 'available work' which in turn closely equals a more easily derivable thermodynamic property, the Gibbs free energy. And indeed in any refined study in energy analysis such as the assessment of waste, for instance, it is the free energy that should be measured.

Nevertheless, the members of the workshop recognised that the calculation of Free Energy would not always be possible and is in any event little understood. For most situations an error of no more than $10 \%$ is incurred in taking enthalpy, that is the heating value of a fuel when it combusts with air. This quantity is called the Gross Energy Requirement (GER), normally expressed in megajoules (MJ) or gigajoules (GJ) per unit of output. The workshop defined it as "the amount of energy source or sources which are sequestered by the process of making a good or service". To obtain the "energy" content, the workshop recommended the convention that it be taken as the gross heat of combustion with air at 1 bar pressure and $\mathrm{O}^{\circ} \mathrm{C}$.

The ramifications of this concept may be gathered from Fig. 1, in which is depicted a hypothetical production process in which natural gas, feed-stock hydrogen and silicon dioxide (from sand) combine to yield a product $Y$. Suppose that the energy to drive the process comes from coal. There are three system boundaries, of which the inner may be likened to the factory fence, and is essentially the system boundary a dopted by company accountants.

The inputs entering through the inner boundary have to be prepared and delivered. Thus silicon dioxide must be refined by (say) acid treatment of sand, hydrogen must be made from natural gas, and natural gas must be brought to the factory fence. These additional processes are depicted by the middle system boundary, somewhat analogous to the nation state. But in the end all the inputs derive from a source in or on the ground-the outer system boundary. In estimating the GER it is essential to go back to this level. Of course, if one's interest is in the energy efficiency of a given sector of a process, then one may choose to examine what happens in the transfer through one boundary to another. This is referred to as the Process Energy Requirement.

Another valuable permutation is that of Net Energy Requirement (NER).

Fig 1: hypothetical production process

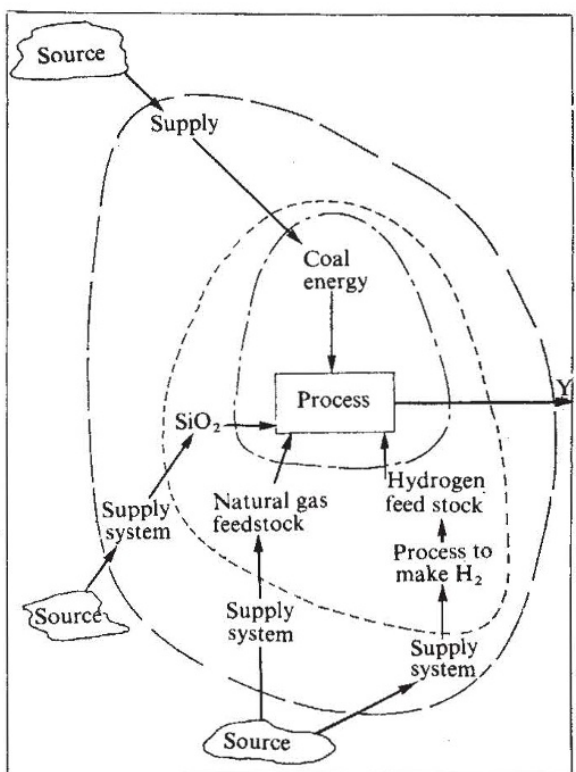

Table 1 The ERE for UK fuel industries

\begin{tabular}{llll}
\hline & 1963 & 1968 & $1971-72$ \\
Coal & 0.047 & 0.042 & 0.047 \\
Gas & 0.48 & 0.390 & 0.23 \\
Oil & 0.23 & 0.134 & 0.11 \\
Electricity & 3.54 & 3.192 & 2.98
\end{tabular}

Source: Chapman et al., Energy Policy, Sept. 1974 .
This is useful in cases in which the product is itself a combustible item, such as a plastic product or a refined fuel. It takes into account the fact that the product has a future potential as a fuel. Clearly in the argument as to whether a plastic or a glass bottle is the less energy intensive, it aids the proponent of plastic bottles to take the NER, rather than the GER, while the manufacturer of the glass bottle cannot take anything but the GER.

Of all the uses of energy analysis and the use of Gross Energy Requirement, perhaps none is more spectacular than the concept of the Energy Requirement for Energy (ERE) defined as (energy of the resource sequestered-energy delivered to point of use)/energy delivered to point of use. Here we use energy analysis to assess the amount of energy that must be sequestered in order to make energy available. Table 1 , for example, relates to some recent UK figures. It shows some facets of our energy industries that are not normally apparent. Thus the efficiency of fuel use for electricity generation is rapidly rising and now exceeds an average thermal efficiency of $31 \%$ at the power station. But if one allows for the energy required to get the coal and nuclear fuels to the power station, the energy dissipated in the grid and that used by the electricity boards themselves, the final ERE for electricity in the UK today is barely below 3.0. That is to say, for every unit of electricity consumed by the public ( $1 \mathrm{kWh}$ $=3.6 \mathrm{MJ}$ ), some $14 \mathrm{MJ}$ of energy have been sequestered.

Estimating energy requirements is not unlike cost accounting with an element of quantity surveying thrown in. One should recognise that various levels of accuracy are necessary. The direct inputs to a process under study must be estimated accurately. But the inputs to the inputs may generally be treated with a lower order of accuracy. Thus if the problem is to estimate the GER of a field of barley. one needs to know the actual inputs to the barley field. These will comprise such things as tractor fuel, nitrogen fentiliser, phosphorus, pesticide and so on. But the GER to make nitrogen fertiliser need not generally be estimated in such detail. Indeed an industry-wide aggregate based on the GER per unit of nitrogen would be sufficiently accurate. In the same way the machines to make the factories to make the inputs represent a very small part of the whole process, and may be obtained at adequate accuracy from such devices as economic input-output tables.

Perhaps the greatest room for dispute and error is in the partitioning the GER between two or more products of one process. In economics, market forces dictate partitioning. In energy 
analysis, the market mechanism has yet to develop. For example, how does one partition the energy requirements in the case of the electrolysis of common salt to yield chlorine and sodium hydroxide, for each of which the current price is different? The IFIAS workshop recommended that this be done on the basis of some physical parameter, not on notions of value.

Energy analysis has been cursorily dismissed in some economic circles as being no more than "a BTU-theory of value". Energy analysts, however, would neither claim as much nor as little. The potential for energy analysis still has to be tested, just indeed as economic analysis has still to show whether it is sufficiently developed to deal with such problems as resource scarcity or a step change in the price of energy. I shall merely indicate here a few of the areas where energy analysis is being tried out and suggest that it is a logical area of endeavour.

What will be the price of ammonia fertiliser in 1990? It would be a brave man indeed who was prepared to extrapolate price trends that far ahead. Even to guess at a figure for six months from now would have its uncertainties. By using energy terms, the uncertainty largely vanishes. Figure 2 depicts how the GER for ammonia has changed with time since its first synthesis in in 1912. Note how the GER appears to be flattening out at some 2.5 times the theoretical (thermodynamic) minimum. Now the thermodynamic minimum energy presupposes an infiinitely slow rate of transformation-clearly not a practical state of affairs for a world that is looking for large amounts of ammonia every day. It is now clear that there is a trade-off between energy and haste of production, and a study of the new, really large $(300,000$ tonnes a year) ammonia plants suggest that the technological minimum at that rate of production will be not far from the value of 2.5 times the thermodynamic minimum. This simply arises from the need to have preheaters, coolers, heat exchangers and furnaces that are less than $100 \%$ efficient.

We can therefore forecast with reasonable accuracy that the GER for ammonia in 1990 will be about $45 \mathrm{MJ} \mathrm{kg}^{-1}$.

Where less developed processes are being dealt with, of course, an assessment must be made of the effect on the GER of technological improvements and growth in the scale of operations. Economic theory would have to be used to find a means of assessing how quickly these changes might come about under the pressures of demand and supply.

Since all energy is conserved, but high quality energy is degraded to waste heat, waste has several connotations.
In one sense it is the use of more energy than necessary to effect a given transformation. Energy analysis provides the tools for looking at this problem, though it does not of itself provide the answer. Gyftopolous and associates (in Potential fuel effectiveness in industry, Ballinger, Cambridge, Massachusetts, 1974) estimated the Gross Free Energy Requirement (GFER) in various production processes in the USA and found that iron making, at 4.16 times the thermodynamic minimum, was much more efficient than the aluminium industry (7.6), petrol (10) or paper making (170).

But there is another sense in which energy analysis can examine waste. It

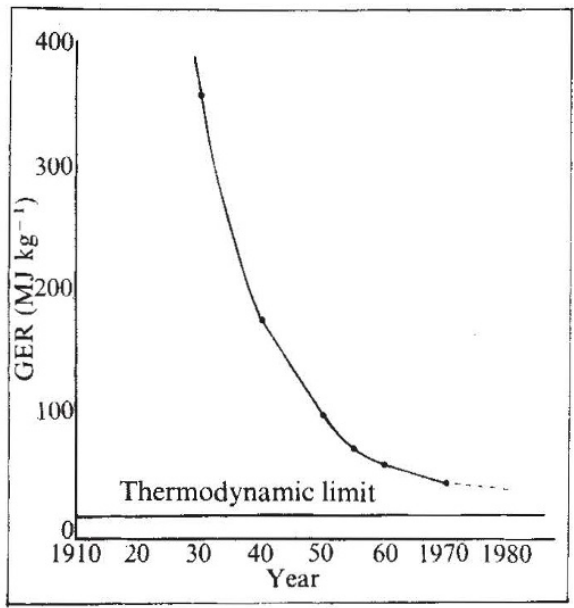

Fig 2: GER for ammonia manufacture

is now recognised that energy dissipation in highly industrialised areas can create climate modification and some climatologists are suggesting that, globally speaking, an energy dissipation equal to $1 \%$ of the incoming solar energy or even less may be an upper limit for the planet. As we approach this limit, probably in the middle of the next century, the matter of interest is not the energy dissipated by the factory in Sheffield, but the energy that had to be dissipated in order to make the Sheffield factory function. And that has to be aggregated over the whole globe. This is exactly what a GER calculation allows one to do so easily.

There are many views of the future energy situation and how the price of oil will vary. It is reasonable to argue that in intelligent hands (and OPEC is intelligent) the price of oil will be slightly lower than its substitution price. But economic substitution calculations based on pre-November 1973 energy prices are now incorrect, because the stepchange in the price of oil has raised the cost of the inputs necessary to furnish alternative forms of energy. So calculation of that substitution price is a very tricky matter. Why not re-express the problem in terms of ERE?

In 1972 it was reckoned that Colo- rado shales would be exploitable at an energy price of $\$ 6$ a barrel, that is when oil prices reached a price of $\$ 6$ per barrel (US Energy Outlook, National Petroleum Council, USA). At that time energy cost somewhat less than \$1 a gigajoule. Allowing for others costs and profit, we deduce that the GER for shale was and is around 5 GJ per barrel. The energy in a barrel of shale oil is about 6.5 GJ per barrel. Thus shale production gives a net ERA of about 0.3 . King Feisal is still sitting pretty.

Such figures are clearly very tentative and not backed by good data. But the data are obtainable.

The ceiling to energy prices will be set when the ERE for unlimited energy is known. Our likely sources are fusion and solar. At the moment the ERE for solar energy by photovoltaic methods is around 2-hopelessly high. New technology in the pipeline may reduce that by a factor of six to 0.33 -better than Colorado shale - but another order of magnitude is needed before solar energy sources can compete with Middle East oil at the well head. The ERE for fusion is a matter for conjecture. In laboratory studies it is still hopelessly high.

And so, finally, we come to the logical intermediate step-to assess the GER to save energy rather to produce it. What, for example, is the GER to double glaze and insulate a house, and what is the GER saved thereby each year? When energy was cheap, economic calculations came up with different solutions. Now they are tending to comc to the same solutions and people, using their own horse sense, are insulating and double glazing their homes and are finding it an extremely attractive long term gain.

One of the most telling uses of cnergy analysis has been the pioneer work by Chapman and Mortimer at the Open University and by Price at Friends of the Earth in their dynamic analysis of nuclear reactor building programmes. They show that no crash programme of nuclear reactor construction can ever meet an energy gap, because of the huge energy investment needed; indeed a net energy deficit would be created for the first eight to eleven years of the programme. At Strathclyde we have carried this analysis a step further using system simulation techniques to examine a range of energy scenarios for the UK to the year 2000 . Though a great deal hinges on the quality of uranium ores that will be available, there seems to be no way a steam generating heavy water reactor system can sustain the rates of economic growth hoped for. Here then, is a new methodology, an old language and a familiar problem - the problem of allocation of resources. 